\title{
Development of contactless solid state voltage relay
}

\author{
Erkin Abduraimov ${ }^{*}$, Dilshad Khalmanov ${ }^{2}$ \\ ${ }^{1}$ Tashkent State Technical University named after Islam Karimov, Department of "Electrical Engineering", of the Electrical \\ Energy Faculty, Tashkent, University St. 2A, 100095, Uzbekistan \\ ${ }^{2}$ Tashkent State Technical University named after Islam Karimov, Department of "Electrical Engineering", of the Electrical \\ Energy Faculty, Tashkent, University St. 2A, 100095, Uzbekistan
}

\begin{abstract}
The article deals with the research issues of compact, reliable, high-speed semiconductor solidstate non-contact voltage relays with an increased service life, combining a sensitive system and a powerful actuator with a sinusoidal voltage curve at the load. Theoretical studies of a controlled resistive and nonautonomous dynamic circuit, consisting of a thyristor connected in series with a parallel circuit containing a capacitance and an active resistance, under the influence of an external sinusoidal voltage, which can be used in control circuits of power thyristors, are presented. An experimental characteristic is shown with a description of the operating principle of the developed solid-state non-contact voltage relay.
\end{abstract}

\section{Introduction}

Achievements in power semiconductor electronics made it possible to use more compact, durable, high-speed optoelectronic and semiconductor analogs instead of transformers, reactors, relays, electromechanical switching devices, rheostats, autotransformers, reactive power regulators when solving complex technical problems aimed at increasing the efficiency of electrical devices. The leading role in this direction is assigned to optoelectronic devices and thyristor devices, which provide contactless switching processes and galvanic isolation, have improved transient and frequency characteristics [1].

\subsection{Theoretical research}

In connection with the widespread automation of production processes and the introduction of automatic control systems, the requirements for the creation of such devices have significantly increased, and the care of these devices during operation should be reduced to a minimum. These requirements are largely met by noncontact electrical devices [2].

Important advantages of non-contact devices are their speed, inertia, high selectivity in protection, increased service life and reliability, manufacturability of the design, lack of precise assembly requirements, practically unlimited switching frequency, the ability to regulate output parameters according to a given law, the possibility of using the same type of devices in networks of different voltages by replacing thyristors with thyristors of a different class, admissibility of operation in the most difficult climatic conditions, simplicity of design in an explosive design $[3,4]$.
Nowadays, more and more occupy a place in modern technological areas such as communication systems, consumer electronics and industrial automation, i.e. there is an intensive transition from conventional switching schemes using conventional electromagnetic relays and moving contact starters to more reliable switching tools such as solid-state semiconductor relays.

Solid state relays can consist of powerful semiconductor elements that replace the contacts of electromagnetic devices (relays, starters, and contactors). Solid state relays currently available can switch high load currents. Moreover, in such relays there is no need for galvanic isolation of the control circuit from its power section.

One of the circuit solutions of contactless devices is a controlled resistive circuit shown in Fig. 1.a.

The current in this circuit flows only when the thyristor is open. This is possible at certain values of the source voltage and thyristor control current. For this circuit, when the input voltage is higher than the thyristor turnon voltage and the control current is greater than the minimum thyristor control current, an abrupt opening of the thyristor is observed with a turn-on angle equal to $90^{\circ}$, i.e. this phenomenon can be called the triggering effect of the resistive circuit.

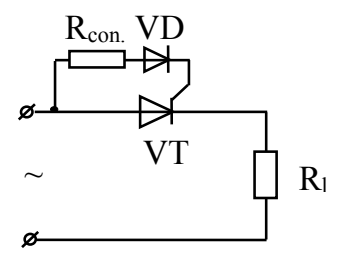

a)

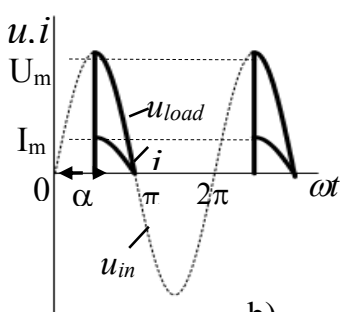

b)
Fig. 1. a) Explored circuit, b) load current and voltage curves 
It is known that by controlling the triggering moment of the thyristor it is possible to influence the shape of the load current curve. If the phase shift $\varphi$ between the beginning of the "positive" half-period of the anode voltage and the beginning of the forward current is equal to zero, the shape of the load current curve will be sinusoidal.

Figure 1.b) shows the shapes of the voltage and load current curves, where at a sinusoidal voltage of the source and when the thyristor is opened with an angle $\alpha=\pi / 2$, the voltage across the resistance will change abruptly to the amplitude value of the alternating voltage. Therefore, for an angle of $90^{\circ}$, the average and effective values of the current in the circuit are determined as follows: $\alpha<\omega t<\pi$

$$
\begin{gathered}
i=\frac{U_{\text {in } \max }}{R} \operatorname{Sin} \omega t=I_{m} \operatorname{Sin} \omega t \\
I_{\text {mid }}=\frac{1}{2 \pi} \int_{\alpha}^{\pi} I_{m} \operatorname{Sin} \omega t d \omega t= \\
=\frac{1}{2 \pi} I_{m}(1+\operatorname{Cos} \alpha)
\end{gathered}
$$

in our case for $\alpha=90^{\circ} \quad I_{\text {mid }}=\frac{I_{m}}{2 \pi}$

RMS current:

$$
\begin{array}{r}
I=I_{m} \frac{1}{\sqrt{2 \pi}} \sqrt{\frac{1}{2}(\pi-\alpha)+\frac{1}{4} \operatorname{Sin} 2 \alpha} \\
\text { for } \alpha=90^{\circ} \text { we get, } \quad I=\frac{I_{m}}{\sqrt{2}}
\end{array}
$$

We will also conduct a theoretical analysis of a nonautonomous dynamic circuit consisting of a thyristor connected in series with a parallel circuit containing a capacitance and an active resistance, which is under the influence of an external sinusoidal voltage (Fig. 2.a).

Let us assume that the voltage of the power supply changes in a sinusoidal manner and the thyristor has an ideal characteristic.

Obviously, until the moment $\mathrm{t}=\mathrm{t}_{1}$, the thyristor will be closed, the voltage across the capacitance $C$ will be equal to zero. At the moment $\mathrm{t}=\mathrm{t}_{1}$, the thyristor abruptly opens and a voltage will be applied to the capacitance $C$

$$
\mathrm{u}=\mathrm{U}_{\mathrm{m}} \operatorname{Sin} \omega \mathrm{t} \quad\left(t_{1} \leq t \leq t_{2}\right)
$$

from the moment of time $t_{2}$ the current through the thyristor takes on zero value.

We write the expression for the current flowing through the thyristor

$$
\begin{aligned}
& i=i_{R_{\text {load }}}+i_{C}=\frac{U_{m}}{R_{\text {load }}} \operatorname{Sin} \omega t+U_{m} \omega \operatorname{Cos} \omega t= \\
& =U_{m} \sqrt{\omega^{2} C^{2}+1 / R^{2}} \operatorname{Sin}\left(\omega t+\beta_{i}\right)
\end{aligned}
$$

where $\beta_{i}=-\operatorname{arctg} \omega C R_{\text {load }}$
The current will go to zero at $\omega t+\beta_{i}=0$ i.e. at $t_{2}=\pi-\operatorname{arctg} \omega C R_{\text {load }}$

At time $\boldsymbol{t}_{2}$, the voltage across the capacitor $C$ will be equal to the voltage of the source, i.e. $u_{C}=U_{m} \operatorname{Sin} \omega t_{2}$, and the thyristor VT is closed, therefore the capacitor is discharged to the resistance $\mathrm{R}_{\text {load }}$. To determine the law of voltage change across the capacitance, it is necessary to solve the following equation of state of the circuit:

$$
\frac{d u_{C}}{d t}=-\frac{u_{C}}{R C}
$$

Let us determine the value of $\boldsymbol{u}_{c}$ for various points from $\boldsymbol{t}_{2}$ to $\boldsymbol{t}_{3}$ by setting the integration step $\mathrm{h}$.

$$
u_{C_{n}}=u_{C_{n-1}}+\left(-\frac{u_{C_{n-1}}}{R C}\right) h .
$$

Figure 2. b) shows a graph of the voltage across the capacitor, obtained by numerically solving equations (6).

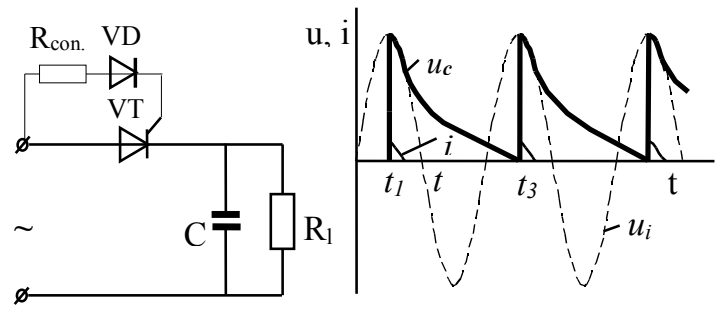

a)

b)

Fig. 2. a) Explored circuit, b) capacitance voltage curves

Thus, the analysis of a non-autonomous dynamic circuit consisting of a thyristor connected in series with a parallel circuit, from a capacitance and an active resistance, can be carried out by numerically solving the equations of state of the circuit $[5,6]$.

\subsection{Practical and experimental research}

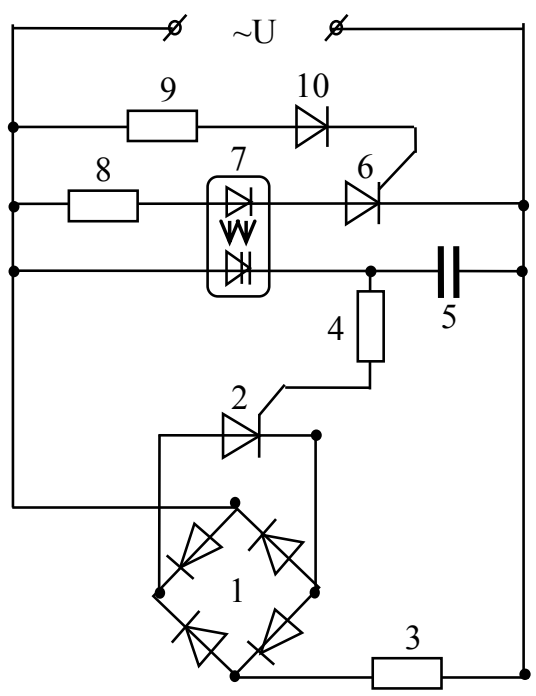

Fig. 3. Circuit of a solid-state non-contact voltage relay 
On the basis of the considered circuits, non-contact voltage relays based on optoelectronic elements with an increased service life were developed, combining a sensitive system and a powerful actuator having a sinusoidal voltage curve at the load.

In fig. 3 shows a schematic diagram of one of our developed semiconductor solid-state contactless voltage relays with sinusoidal voltage across the load and (Fig.4) an experimental characteristic of the input and output of this voltage relay, based on the circuits studied above. The developed non-contact voltage relay works as follows $[7,8,9,10]$.

When a certain value of the input voltage is reached, the unlocking signal on the control electrode will be sufficient to unlock the thyristor 6 , with an opening angle of $90^{\circ}$ and closes the diode circuit of the optocoupler 7 into the network through a resistor. This leads to the flow of current through the diode part of the optocoupler 7 and thereby opens the thyristor part of the optocoupler 7, and the capacitor 5 is included in the network. To control the state of the power thyristor, a thyristor optocoupler is used, and the diode circuit of the optocoupler is connected through a limiting resistor to the capacitor plate, which is connected to the network.

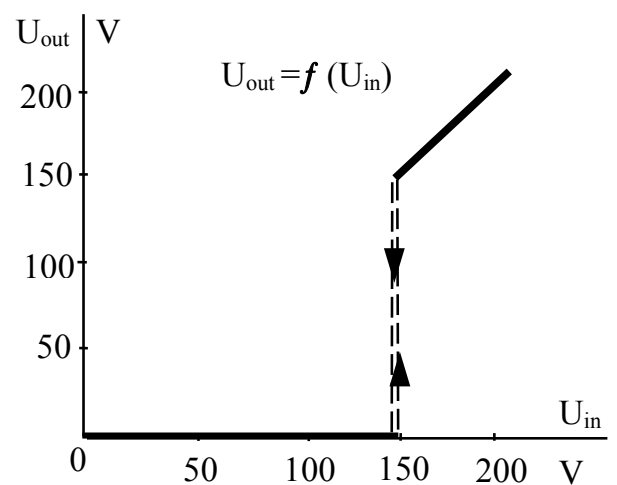

Fig.4. characteristic "input-output"

Since a direct current signal is supplied to the control electrode of thyristor 2 , from the capacitor 5 through the resistor 4 , it remains constantly open, and a sinusoidal current will flow through the load 3. The moment of operation of thyristor 6 is regulated by selecting or changing the parameter of the resistor 9 .

This non-contact voltage relay was tested in the laboratory of the "Electrical Engineering" Department of the Energy Faculty of the Tashkent State Technical University. In this case, thyristors of the type KU 202 I, KU 201I were used as thyristors 2, 6, respectively, as a diode - D $226 \mathrm{~B}$, as active resistance 3,4,8,9 respectively resistors of $820 \mathrm{Ohm}, 15 \mathrm{kOhm}, 3.8 \mathrm{kOhm}, 16 \mathrm{kOhm}$, as a capacitance 5 - a capacitor with a capacity of $1 \mu \mathrm{F}$, as an optocoupler used thyristor optocoupler AOU103V, diode bridge KTs 402 E. .

\section{Conclusion}

Experimental studies have shown that load 3 was connected to the network at a voltage of $150 \mathrm{~V}$. In fig. 4 . the input-output characteristic is given. The voltage waveform across the load is sinusoidal.

\section{References}

1. L.V. Chopin, Contactless electrical automatic devices. M, Energoatomizdat, p. 446 (1986)

2. A.A. Poskrobko, V. B. Bratolyubov. Non-contact switching and control semiconductor devices in alternating current. Moscow. Energy, p. 192, (1978)

3. Bobojanov M.K., Usmanov E.G., AbduraimovE.Kh., Karimov R.Ch. Resistive time delay swishes Seintifie journal "European Science Review” Austria, Vienna, 2018 -№1-2 210-212c PP210-212 (05.00.00; №3)

4. Abduraimov E. Kh., Khalmanov D. Kh. Theoretical analysis of semiconductor circuits. Eurasian Union of Scientists No. 3, 2019 Russia, pp. 60-63.

5. E. G. Usmanov, E. Kh. .Abduraimov, R.Ch. Karimov, the Nonlinear dynamic chain with a tiristor // Problems of informatics and power of the Republic of Uzbekistan, Tashkent, 2006 №. 2,3. p. 37-41

6. Hoshimov, F.A., Bakhadirov, I.I., Erejepov, M., Djumamuratov, B. (2019) Development of method for normalizing electricity consumption $E 3 S \mathrm{Web}$ Conf 139 doi:10.1051/e3sconf/201913901074

7. E. Kh. Abduraimov, Optoelectronic contactless switching devices. Bulletin of Tashkent State Technical University No. 3, pp. 73-78. (2016)

8. Patent RUz No. IAP 05122, Optoelectronic proximity voltage relay, E.G. Usmanov, E.Kh. Abduraimov, R.Ch. Karimov. Publ. in "Rasmiy Akhborot",№ 12. (2015)

9. Patent RUz No. IAP 06122, Time delay optoelectronic voltage relay, E.G. Usmanov, E.Kh. Abduraimov, D. Kh. Khalmanov, R.Ch. Karimov. Publ. in "Official newsletter", №1. P. 225 (2020)

10. E. Kh. Abduraimov, D. Kh. Khalmanov, B. A. Nurmatov, S.A.Dusmukhamedova, N.E. Khamidova. Theoretical research and development optoelectronic communication devices. Journal of Physics: Conference Series 1515022055 IOP (2020)

11. E. Kh. Abduraimov, D. Kh. Khalmanov, S.A.Dusmukhamedova. Analysis of Semiconductor Circuits. International journal of Advanced Science and Technology. Vol.29 No. 11s 1655-1859 (2020) 